\title{
An Overview of Future Scenarios: Where Are We Going With English?
}

\author{
Ersilia Incelli \\ Faculty of Economics, University of Rome Sapienza \\ Rome, Italy \\ E-mail: ersilia.incelli@uniroma1.it
}

Received: February 5, 2021

doi:10.5296/ijl.v13i2.18417
Accepted: March 6, 2021

Published: March 15, 2021

URL: https://doi.org/10.5296/ijl.v13i2.18417

\begin{abstract}
This contribution aims to present an overview of future predictions about the evolution and status of the English language, in particular as a global lingua franca. The paper considers recent events such as Brexit and the emergence of new economic powers, and the fact that other widely spoken languages could compete with the hegemonic longevity of English as a lingua franca. Although English will certainly remain globally dominant for a large part of the 21st century, new geopolitical landscapes may influence the role of English both in Europe and in the world. This overview is not exhaustive in reporting all the variables in the debate, but it wishes to examine the main issues of concern in the future standing of English.
\end{abstract}

Keywords: Lingua franca, Global English, Brexit, Predictions, World Englishes

\section{Introduction}

As a teacher of English in higher education settings, this article is the result of reflections on the broader context of global trends affecting the status of English as a lingua Franca (ELF) and the evolving sociolinguistic landscape of the twenty-first century. Recent phenomena are changing not only how English is perceived in a globalised world, but also how it is taught and learnt. The following considerations based on current data are intended as a premise for further empirical research in the field of Global English, used here as an umbrella term to include overlapping fields of World Englishes (Kachru and Nelson 2006), English as an international language and ELF (Seidlhofer 2011; Rose and Galloway 2019).

At present, there is no doubt that English enjoys hegemony as the global lingua franca, acting as an indispensable tool for communication between people of different languages and 
cultures, moreover it is expected to remain the most extensively used language probably for the rest of this century (Crystal 2003; Graddol 2004; 2013). Indeed, English is currently spoken by over 1.132 billion people in the world, with approximately 753 million non-native speakers of English, and around 379 million native speakers of English, most of whom are located in Great Britain and the United States (World Population Review 2020). It is still the most widely spoken language in 75 countries where it is considered the official language, or the de facto language, that is, the language used by the majority of speakers. That being the case, English is far more frequently spoken as a second or third language than as a first language, consequently it is no longer exclusively owned by its native speakers, with 'native English' now in minority usage on a global scale (Seidlhofer 2011; Rose et al., 2020).

Nevertheless, in the light of recent major events like Brexit, and the emergence of Eastern and South-eastern Asian economic powers such as China and India, it is noteworthy to examine the future scenarios for English as a language. The impact of such contexts on global trade, world financial markets, diplomacy and international geopolitical stages, will in the long run affect linguistic and cultural landscapes. Undoubtedly, it would be misleading and deceptive to attempt to predict the future like in a crystal ball but, by looking at what is happening now in the world, it is possible to identify trends and common themes, especially regarding language (Crystal 2003:120). Inevitably, the process of increasingly rapid globalisation associated with fast paced technological progress no doubt represents new opportunities, but this also brings about significant challenges.

As this study aims to provide a general description and exploration of predictions on the future of the English language, it does not profess to follow a traditional academic or scientific method for collecting data or for carrying out empirical observations and surveys, such as action research in the language classroom. Nonetheless, this synopsis can be viewed as a pretext for gathering broader and further empirical evidence on the status of the English language. Therefore, building on existing knowledge in the field, I drew on the following research questions: what factors in current research on global English can contribute to an understanding of the future? What are the implications for future practice in the field of English language teaching?

To answer the above questions, I used the basic method of looking for databases which could provide state-of-the-art data indicating trends. For example, I was inspired by the database of international news stories monitored by Global English Newsletter (GEN created by the English Company UK, which was the first to publish The future of English in 1997). The database has a collection of news stories about English around the world. This way I was able to access state-of-the-art research. I also consulted the latest statistics from world reports such as the World Population Review (2020), and recent European Commission reports for multilingualism (2016).

Of course, an overview of the situation has its limitations, the main limitation being that this work does not consist of action research or in situ observations in the English language classroom generating authentic data in dynamic contexts. The next stage of course, will be to carry out observation surveys which can be particularly fruitful in a classroom of 
international students. For example, in our university context, language classes often involve students from the European Erasmus exchange programme which consists not only of exchange students from all over Europe, but also from countries in South America and East Asia. This sort of situation can provide interesting empirical data based on classroom observations during language learning activities.

Before moving on to describing trends, we can start by looking first at the historical settings for English as a global lingua franca.

\section{Global English}

First of all, in order to understand the merits of the English language, as well as the controversial drawbacks and implications of a dominant global language, we must first understand something of the historical circumstances that facilitated the development of English as a global lingua franca and preserved it as a universal language (Salvi 2002). The unique status that English enjoys today has its roots in historical contexts and their developments (see Crsytal 2003; Hogg, Denison 2006), and in socio-cultural movements which contributed to the language's social prestige, such as the rise of the British Empire. In fact, English spread rapidly on a global scale during the $18^{\text {th }}$ century with British colonialism in Asia, Africa and North America, and in the period of the Industrial Revolution, which projected Britain on the world stage of the $19^{\text {th }}$ and $20^{\text {th }}$ centuries as the main economic power. As Crystal (2003:9) explains, a language becomes truly global and international through 'the power of its people', in terms of economic, political and military might; subsequently the role of the USA after winning the second World War, contributed to the expansion and maintenance of English as the de facto international world language. Today over half of the world's population are in some way exposed to it, and although there is much debate on the linguistic and cultural imperialism of English, the situation is unlikely to change in the next 50 years, with half the world more or less proficient in English (The Economist 2001; 2014).

However, the dominance of English reflects a growing asymmetry between languages of lesser and greater diffusion and has been criticized on many occasions. As already mentioned, there is great controversy over whether English as a global language has brought as many risks as benefits, with consensus on this issue far from being reached (Salvi 2002). This contribution continues with a general overview of both sides of the debate: the threat English poses on other languages and the evolution of the English language as we know it, which is in itself controversial. Crystal (2003:141) aptly puts it, "The loss of ownership is of course uncomfortable to those, especially in Britain, who feel that the language is theirs by historical right; but they have no alternative".

\section{The Impact of English on Other Languages}

Studies by linguists, sociologists and anthropologists, provide evidence that of the 6000 languages existing in the world today, as many as $90 \%$ may be doomed to extinction by the end of this century (Crystal 2000). Graddol (2004) sees the world's language system at a crossroads, with a new linguistic order about to emerge. "Linguistic diversity is being lost at a 
faster rate than biodiversity." (Note 1) Likewise, Wade Davis (2010) reports studies which reveal that, on average every 15 days, the death of an elderly person causes the 'death' of an 'old' language or dialect, leading to 'the extinction of a culture, the 'soul' of a language' (ibid 2010:72). Indeed, every language has its own uniqueness and social heritage, and the loss of any language can be viewed as a human tragedy. An example is provided by the Dalmatian language at the end of the $18^{\text {th }}$ century, which died when the last person to speak it died in 1898, just one among hundreds of extinct languages. Graddol (2004) also anticipates a problem for strong traditional languages which are not spoken outside their national borders, for example Swedish. Such languages could lose their practical use, as economic, political and cultural communication becomes increasingly international. "Swedish, like many European languages, is now more a local language of solidarity than one for science, university education, or European communication." (Graddol, cited in Lovgren 2004).

As long as English is considered the window to wider scope and opportunity in life, and the means to education, knowledge and better job opportunities, it will remain the preferred choice for second language acquisition in most parts of the world, a 'must' on the school curriculum. In certain contexts (but not all) this is occurring at the expense of a person's own native language. Undeniably, governments need to take necessary actions to monitor this situation. However, if governments wish to participate on the economic political and scientific global stage, it is in their best interest they guarantee their citizens the opportunity to learn English through official language policy programmes (Incelli 2008); this of course should not reduce the importance of other languages or lead to the 'disappearance' of other languages.

The European Union has taken to heart its commitment to 'Unity in diversity' and for this reason, the European Commission has made concrete steps to promote multilingualism in Europe, laying down a number of framework strategies to ensure language policy programmes which encourage all European citizens to learn and speak more languages for mutual communication and understanding. The EU 's multilingualism policy has also taken actions to ensure that citizens have access to EU legislation and procedures in their own language (Note 2).

Various scholars have predicted that English will paradoxically create new generations of bilingual and multilingual speakers around the world. There are now many Englishes, which came about predominantly because of the World Englishes movement led by Braj Kachru, as well as leading British scholars like David Crystal, Jennifer Jenkins, among others. The general consensus now is that the acquisition of English language skills does not necessarily mean the replacement of the native tongue. Proficiency in one or more indigenous or native tongues can co-exist, mingle, and/or exist in usage with English. Graddol (2000) proves this point by giving examples of how speakers employ 'code-switching' in conversation (Note 3); that is, two or more participants, (often in a business context such as business negotiations), switch back and forth between English and a local language (the vernacular), constructing their relationship according to the situation, (this often involves hierarchical status and power relations). The following excerpt from Graddol (2000), illustrates how language code-switching occurs between a manager and a young man at a job interview in an office in 
Nairobi, Kenya. The manager, who knows English, insists on the official national language Swahili, probably as a form of respect.

Young Man: MrMuchuki has sent me to you about the job you put in the paper.

Manager: Uitumabarua ya application? [Did you send a letter of application?]

Young Man: Yes,I did. But he asked me to come to see you today.

Manager: Ikiwaulituma barua, nenda ungojee majibu. Tutakuita ufike kwa interviewsiku itakapofika. [If you've written a letter, then go and wait for a response. We will call you for an interview when the letter arrives.] (Graddol 2000:13).

The excerpt also illustrates how code-switching can appear within the same sentence. Code-switching today is commonly used as a strategy in business negotiations, particularly in Asian companies. In fact, as Graddol states, employers in parts of Asia are already looking beyond English. In the near future, scholars are considering the new 'must-learn language' as likely to be Mandarin, to which we will now turn.

\section{Other Global Languages}

Although English enjoys a distinguished position at present and perhaps for the next 50 years, there is no denying that there will be other languages competing with English in the future (Graddol 2013). In truth, Mandarin Chinese ranks the most widely spoken language by native speakers with roughly 1.12 billion speakers (Duffin 2020), but it is the official language only in the People's Republic of China, Singapore and Taiwan (Pariona 2017). Moreover, while the largest population of the world speaks Chinese Mandarin, as yet it does not have enough impact beyond the Chinese borders. Hence, it is still far from being considered an international language. The other two widely used languages are Hindi (currently spoken by 637 million people) and Spanish (spoken by 538 million people). Of relevance, is the fact that the above languages have not replaced English on the Internet, the single major influential medium for international communication and transactions. In 2020, approximately 1.187 billion internet users communicated in English, accounting for $25.9 \%$ of all the world internet users. Mandarin users rank second with 888 million users, as $19.4 \%$ of global internet users (Note 4). It is most likely that no other language will control the internet in the near future (Albey 2008).

Nevertheless, there is evidence that this situation could change. China is now considered a world economic power, with all the political and scientific consequences this entails (Kennedy 2018). There is already indication of China's takeover in areas of scientific research and information technology (UNESCO Science Report 2010).

The impact of China's position on the world stage will certainly have repercussions on global systems and may even lead to the use of Mandarin on the international scene. Although such an event seems implausible, according to Crystal (2003) language tends to change based on changes in society. China's constant modernisation and its driving need for resources are particularly evident in Africa, where there is a growing Chinese population (for example, in Madagascar, Nigeria and Uganda). Recent studies (Chidiebere et al. 2019), have found that, 
overall, African countries where Chinese companies and industry are significantly present, and have notably contributed to the economic development and health of the population, tend towards a positive view of China's cultural influence. Consequently, Mandarin is being considered for the language curriculum in public primary and secondary schools. Nonetheless, it is widely acknowledged that Chinese is a difficult language to learn, presenting a huge barrier to its widespread adoption and circulation. To illustrate, it is estimated you need to learn 2000-3000 characters to read a newspaper. An educated Chinese native knows about 9000 characters.

There may also be foreseeable consequences from Brexit, which could reduce the authority of Britain in Europe. The former President of the EU Commission Jean-Claude Juncker went as far as to say that the importance of the English language will most likely diminish in the coming decade in the EU (Rankin 2017). The repercussions could be exponentially significant in the future if European nations seek an alternative language, such as French which is already used widely in West Africa. However, diplomats still prefer to speak English and it is highly unlikely that the French language (or Spanish) will replace English soon. What is more, any changes in the institutional use of English as a lingua franca in EU institutions needs to be ratified by the European Council of Ministers. In other words, any change to the EU Institutions' language regime is subject to a unanimous vote (European Commission 2016).

According to Modiano (2017) the exit of the UK may give birth to a European English (Euro-English) influenced both by standard English and by L2 English speakers. In this way the position of English in Europe can only be strengthened, the hypothesis being, with Britain gone, continental Europe suddenly has a common language where all involved are users of an L2 English.

However, Brexit may notably dwindle the preference of foreign nationalities to travel to the UK to learn English. For example, an immediate visible effect was the withdrawal of the UK from the European Erasmus student mobility education scheme (in January 2021). Such a manoeuvre will make it very expensive for students to study in England and Great Britain, and vice versa for British students to study abroad. The omission of Erasmus from the UK-EU deal ends a scheme that had offered student exchanges since 1987, as well as work experience and apprenticeships across Europe. Under the latest version of the scheme Erasmus+, around 200,000 people had taken part, involving 15,000 British university students each year. According to a recent report, the estimated cost for ending Erasmus membership will be more than $£ 200$ m a year for the UK suggesting British universities will miss out on a significant source of income (Adams 2020).

Another challenge comes from technology and the evolving pace of machine translation. Developments in translation technology might even do away entirely with the need to speak a foreign language, with implications for interpreting (Lustig 2018) (Note 5). Traditionally media was presented in one language alone which was primarily English, whereas films nowadays have dubbed dialogue. Streaming giants like Netflix dub films in over 10 languages and they can also provide subtitles in twenty-seven different languages (Goldsmith 
2019). Thus, the ease of translating languages eliminates the need to learn an unfamiliar language. In fact, more recently, attendees of international forums such as the United Nations translate entire conversations into their native tongue in real time. As a consequence, people may not be motivated to learn English in the future.

These above-mentioned variables are factors which could indeed reverse the role of English as a lingua franca, and lead one to wonder whether English will remain the world's most influential language in the long term.

\section{The Evolution of English as a Language}

Language is an open system, and English more so than other languages, has since its origin, historically adapted to and incorporated other language influences, comprising Latin, Celtic, Scandinavian and Norman French. This explains the inconsistencies in its syntax, grammar and spelling. Scholars say it is precisely the irregularity and flexibility of English which accounts for its durability and vivacity (Graddol 2000:6). The 'permeability' of the language inherently makes it easy to assimilate characteristics of other cultures and languages, (e.g. Indian English, Malaysian English). In other words, English wholeheartedly absorbs and accepts words and expressions from other languages and dialects. For this reason, as any living language, English will get modified, which explains the preoccupation with how much English will change and to what extent it should change because of its hybridized nature and constant evolution. This has given rise to the much controversialized issue in language teaching regarding which English should be taught to learners (Hempel 2009). It is not the purpose of this paper to discuss this aspect of English language teaching and second language acquisition, but it is one of the many challenges facing English language teachers worldwide (Kachru 1982) (Note 6). New important questions are posed for teachers, for example what do teachers aim to teach students? To achieve native speaker competence or to speak well enough to be able to communicate with English speakers? As we can see, the native speaker model is today more and more regarded as unrealistic, but what then becomes the new framework? There is a growing consensus for the intercultural speaker who can communicate successfully in cross cultural contexts. This concept sheds some light on alternative sources of materials and activities which are beginning to implement intercultural elements in a syllabus.

As far as the evolution of English is concerned, the excerpt below from Mark Abley's book The Prodigal Tongue (2008) illustrates how English has been transformed and will continue to be transformed. According to Abley, the major changes in a language come from people who have the power, capacity and creativeness to modify and invent grammar and vocabulary. The extract reveals the deep flux in contemporary English, with its accommodation of alien terms and infiltration of other cultures.

I asked each student to jot down a few words or phrases that older people would not understand, and then provide a brief definition for each term. [... ]. "You mean any words?" said a preppy-looking girl in blue. "Even the ones that aren't in the dictionary?" "Especially the ones that aren't in a dictionary," I replied. [...]; I thought that all together, the students might come up with a dozen words I didn't know. So much for the vanity of age. 
Cheddar, said the first, meaning "money, lavish earnings." (I'll give this and all the other definitions in the students' exact words.) He got owned, said another: "rejected, shut down, beat up." On the go, added a third: "it's like going out, but not official." I recognized some of the expressions, of course; even a senior citizen of fifty can comprehend eye candy and loaded, poser and flame. Did these innocent, cool teenagers really believe their generation had invented high? But as I stood there in the sun-dappled library, I realized that the majority of the students 'words and phrases left me bemused. What on earth was burninate? Was d-low somehow related to "below," "delay," "J. Lo." - or to none of those terms? (Not wanting to keep the meanings secret - to d-low them, that is - I'll suggest that you'd burninate something only if you had the fire-breathing powers of a dragon.) More generally, by what learned or instinctive command had these young people enacted their self-assured takeover of the language?'(Abley 2008:5)

\section{Conclusion}

Predictions about the future can be annoying and flawed, but the unveiling of present circumstances lays the ground for trends in the next half of the $21^{\text {st }}$ century. In Europe, bilingual education is gaining ground, with English being viewed as an international language for content integrated approaches, promoting fluency in large sections of the population in many countries (Thompson 2018). In fact, there is a growing trend, where English appears to be gaining importance in school and higher education curricula, not only as a subject, but in terms of 'Content and Language Integrated Learning' (CLIL), (Thompson, McKinley 2018; Cenoz et al., 2014). Such developments could increase the demand for English speaking teachers who are specialized in specific subjects. This gives rise to concern about whether English can contribute to the potential obliteration of cultural diversity. On the other hand, there is an increasing amount of evidence (and this is an area which calls for more empirical studies) that it is certainly possible for English to co-exist naturally and effortlessly with other languages, on a parallel level (Kachru 1992; Crystal 2010). The challenge is how to reach and maintain this balanced approach in order to view only the positive benefits of English as a global language which can fully fulfil people's needs. I finish here with a quote from Abley (2008:3), which epitomizes how the English language is a parallel universe to progress and technology. Language and virtual spaces are the future, presenting a vast area of exploration and discovery, like discovering new continents and new languages and cultures.

Language enables us to feel at home in everyday life [...], but of late language seems to have [...] taken the open road. [...]. We find ourselves on the move. Every few days [...] we become aware of a new word or phrase speeding past us. There's no going back either. No retreat into the grammar or lexicon of the past. Our only home is this: the verbal space in which we're already travelling. The expressions in that space are often amazing -. (Abley 2008:3)

To conclude, future studies for this type of research involve empirical observation and analysis of in situ English language classes in order to redefine the concept of appropriate pedagogy for English as a global language, to encourage language teaching that promotes not only international exchange, but also cultural integrity in a globalised world. 


\section{Macrothink}

International Journal of Linguistics

ISSN 1948-5425

2021, Vol. 13, No. 2

\section{References}

Abley, M. (2008). The prodigal tongue: dispatches from the future of English. Houghton Mifflin, Harcourt.

Adams, R. (2020). UK students lose Erasmus membership in Brexit deal. The Guardian. Retrieved December 24, 2020, from https://www.theguardian.com/education/2020/dec/24/uk-students-lose-erasmus-membershipi n-brexit-deal

Chidiebere, E., Xu, L. E., Ehizuelen, H., \& Yang, S. M. (2019). Acceptability of Chinese language education in public primary and secondary schools in Nigerian. International Journal of Multidisciplinary Research and Development, 6(3), 56-63.

Crystal, D. (2000). Language death. Cambridge, Cambridge University Press.

Crystal, D. (2003). English as the global language. Cambridge, New York, Cambridge University Press.

Crystal, D. (2010). A little book of language. UNSW Press.

Davis, W. (2010). Ultime della loro stirpe!. Le Scienze, 71-73.

Duffin, E. (2020). The most spoken languages worldwide in 2019. Statista. Retrieved from https://www.statista.com/statistics/266808/the-most-spoken-languages-worldwide/

European Commission. (2016). Retrieved from https://ec.europa.eu/ireland/news/statement-on-behalf-of-theEuropean-Commission-Represen tation_en

Goldsmith, J. (2019). Netflix wants to make its dubbed foreign shows less dubby. The New York Times. April 3, Retrieved 2020, from https://www.nytimes.com/2019/07/19/arts/television/netflix-money-heist.html

Graddol, D. (2000). The Future of English? A guide to forecasting the popularity of English language in the $21^{\text {st }}$ Century. British Council. Retrieved from http://www.ocol-clo.gc.ca/docs/f/Future_of_English.pdf

Graddol, D. (2006). English Next. Why global English may mean the end of 'English as a Foreign Language'. British Council. Retrieved from http://www.britishcouncil.org/learning-research-english- next.pdf

Graddol, D. (2013). Profiling English in China: The Pearl River delta. Cambridge: Cambridge English Language Assessment. Retrieved from https://www.cambridgeenglish.org/Images/151564-profiling-english-in-china-dg.pdf

Harmon, D. (1996). Losing species, losing languages: Connections between biological and linguistic diversity. Southwest Journal of Linguistics, 15(1/2).

Hempel, M. (2009). Global English: English is changing the world - in what way is the world changing the English language and the way it will be taught?. GRIN Verlag, Norderstedt 
Germany.

Hogg, R., \& Denison, D. (2006). A history of the English language. Cambridge, Cambridge University Press.

Incelli, E. (2008). Foreign language management in Lazio SMEs. Language Policy, 7(2), 99-120.

Kachru, B. (1992). Teaching world Englishes. In B. Kachru (Ed.), The other tongue: English across cultures (2nd ed.). Urbana, IL: University of Illinois Press.

Kachru, Y., \& Nelson, C. L. (2006). World Englishes in Asian contexts. Hong Kong, Hong Kong University Press.

Kennedy, S. (2018). China will overtake the U.S. economy in less than 15 years, says HSBC, challenging Trump's claim. Financial Post, 25 September.

Lovgren, S. (2004). English in decline as a first language, study says. National Geographic News. Retrieved from http://news.nationalgeographic.com/news/2004/02/0226_040226_language.html

Lustig, R. (2018). Can English remain the world's favourite language (BBC, 23 May).

Modiano, M. (2017). English in a post-Brexit European Union. World Englishes, 36(1), 313-327.

Pariona, A. (2017). The most popular official languages of the world. World Atlas. Retrieved from

https://www.worldatlas.com/articles/the-most-popular-official-languages-of-the-world.html

Rankin, J. (2017). Brexit: English is losing its importance in Europe, says Juncker. The Guardian, $5 . \quad$ Retrieved from https://www.theguardian.com/politics/2017/may/05/brexit-english-is-losing-its-importance-in -europe-says-juncker

Rose, H., \& Galloway, N. (2019). Global Englishes for language teaching. Cambridge, Cambridge University Press.

Rose, H., Mckinley, J., \& Galloway, N. (2020, November). Global Englishes and language teaching: a review of pedagogical research. Language Teaching.

Salvi, R. (2002). Global English. A Global Debate. Milano, LED.

Seidlhofer, B. (2011). Understanding English as a lingua franca. Oxford, Oxford University Press.

The Economist. (2001). The triumph of English: a world empire by other means.

The Economist. (2014). Future English: Simpler and more foreign.

Thompson, G., \& Mckinley, J. (2018). Integration of content and language learning. TESOL Encyclopedia of English Language Teaching. 


\section{Macrothink}

International Journal of Linguistics

ISSN 1948-5425

2021, Vol. 13, No. 2

$\begin{array}{lllll}\text { UNESCO Science } & \text { Report. } & \text { (2010). } & \text { Retrieved }\end{array}$ http://unesdoc.unesco.org/images/0018/001899/189958E.pdf

World Population Review. (2020). Most Spoken Languages 2020. World Population Review. Retrieved from https://worldpopulationreview.com/articles/most-spoken-languages/

\section{Notes}

Note 1. Interview with Graddol by Lovgren 2004: http://news.nationalgeographic.com/news/2004/02/0226_040226_language.html. (accessed January, 2017). See also Harmon (1996) for a detailed discussion on biological and linguistic diversity.

Note 2. The EU Commission (2005), 'A new framework strategy for multilingualism' and 'Action plan promoting language learning and linguistic diversity':

http://eur-lex.europa.eu/LexUriServ/LexUriServ.do?uri=COM:2005:0596:FIN:EN:PDF (accessed June, 2018).

Note 3. See the following for a discussion of code-switching in linguistics: Myers-Scotton, Carol (1989), "Codeswitching with English: types of switching, types of communities", in World Englishes, 8 (3), pp. 333-346; Heller, Monica (1992), "The Politics of Codeswitching and Language Choice", in Eastman, C. (ed.) Codeswitching. Clevedon, Multilingual Matters.

Note 4. https://wearesocial.com/digital-2020 (accessed June 2020).

Note 5. See also Lustig (2018) "From Language to Algorithm, The Future of English": https://www.bbc.co.uk/programmes/w3csxgb7 (accessed June, 2019).

Note 6. See also an interview with David Crystal (2009) http://www.macmillanglobal.com/blog/teaching-tips/which-english-should-we-teach-david-cr ystal (accessed 10th January 2015).

\section{Copyrights}

Copyright for this article is retained by the author(s), with first publication rights granted to the journal.

This is an open-access article distributed under the terms and conditions of the Creative Commons Attribution license (http://creativecommons.org/licenses/by/4.0/) 